\title{
Hospital discharge on the first compared with the second day after a planned cesarean delivery had equivalent maternal postpartum outcomes: a randomized single-blind controlled clinical trial
}

Parvin Ghaffari ${ }^{1}$, Raziyeh Vanda', Shahintaj Aramesh', Leila Jamali ${ }^{1}$, Fatemeh Bazarganipour ${ }^{2^{*}}$ and Mohammad Amin Ghatee ${ }^{3}$

\begin{abstract}
Objective: Determining the effect of discharge time after elective cesarean section on maternal outcomes.

Methods: This study is a randomized clinical trial that performed on 294 women who undergo elective cesarean section. The patients were randomized in two groups by simple randomization method: Group A (discharge $24 \mathrm{~h}$ after cesarean) and group B (discharge for $48 \mathrm{~h}$ after cesarean). In both groups, during the first $24 \mathrm{~h}$, they received intravenous antibiotic (cefazolin as routine order) and pethidine at the time of pain. The patients were discharged with the hematinic and mefenamic acid. The main outcome variables were satisfaction of the patient, surgical site infection, separation of incision, endometritis, urinary tract infection, gastrointestinal complications, rehospitalization, secondary postpartum hemorrhage and pain of the patient on discharge day, one and six weeks after cesarean.
\end{abstract}

Results: Satisfaction scores and pain score at discharge day, one and six weeks after discharge were not significant different in the study groups $(P>0.05)$. Another key finding of this paper was no significant difference in the incidence of surgical site infection, separation of incision, endometritis, urinary tract infection, gastrointestinal complications, rehospitalization, secondary postpartum hemorrhage at one and six weeks after discharge in the study $\operatorname{groups}(P>0.05)$.

Conclusion: The time of discharge can be reduced to $24 \mathrm{~h}$ after surgery if the mother to be at good general condition, the vital signs are stable, the patient has no underlying problem and disease, and it is financed for the patient and the health system.

Keywords: Cesarean, Early discharge, Maternal outcomes

\footnotetext{
* Correspondence: f.bazarganipour@gmail.com

${ }^{2}$ Social Determinants of Health Research Center, Yasuj University of Medical Sciences, Yasuj, Iran

Full list of author information is available at the end of the article
}

C C The Author(s). 2021 Open Access This article is licensed under a Creative Commons Attribution 4.0 International License, which permits use, sharing, adaptation, distribution and reproduction in any medium or format, as long as you give appropriate credit to the original author(s) and the source, provide a link to the Creative Commons licence, and indicate if changes were made. The images or other third party material in this article are included in the article's Creative Commons licence, unless indicated otherwise in a credit line to the material. If material is not included in the article's Creative Commons licence and your intended use is not permitted by statutory regulation or exceeds the permitted use, you will need to obtain permission directly from the copyright holder. To view a copy of this licence, visit http://creativecommons.org/licenses/by/4.0/ The Creative Commons Public Domain Dedication waiver (http://creativecommons.org/publicdomain/zero/1.0/) applies to the data made available in this article, unless otherwise stated in a credit line to the data. 


\section{Introduction}

Cesarean delivery (CS) is one of the major surgeries in midwifery and its consequences and complications are a major concern of health services. The rate of cesarean delivery worldwide has increased from 21\% in 1997 to $33 \%$ in 2008 [1]. In the United States, cesarean delivery occurs in one-third of deliveries and women are hospitalized 3-4 days after the procedure. According to The American College of midwifery and gynecology shorter discharges are a choice if the baby is ready to go home, though, the mother should have basic requirements such as normal blood pressure, no symptoms of infection, and adequate pain control [2]. Postpartum stay at hospital is steadily declining in the UK and other countries due to cost savings. Rising hospital costs are one of the factors in early discharge [3].

Several studies have evaluated early discharge after cesarean delivery. Some of study proposed that the length of hospital stay is probably longer after CS (average 3-4 days) than vaginal delivery (average 1-2 days). But according to National Institute for Health and Care Excellence (NICE). (2019), women who are recovering well, are apyrexialand do not have complications, should be discharged early (after $24 \mathrm{~h}$ ) and followed at home because this is not related to the readmission of the baby or mother. However, other studies have shown that short stays may not leave enough time to diagnose, or treat complications, which in turn can increase morbidity and mortality [4-6]. Fasuba et al. (2000) evaluated the reduction in hospital stay after cesarean delivery and concluded that early discharge may decrease some of the psychological and economic concerns associated with surgery, which is highly acceptable [7]. In another study, Umbeli et.al (2012). evaluated patient"s satisfaction and mortality associated with elective cesarean delivery with $24 \mathrm{~h}$ postpartum, and the researchers reported that short stays after Cesarean delivery was associated with greater patient"s satisfaction and no increase in maternal mortality compared to the control group [8]. Early discharge will be reducing hospital care and patient"s costs and improves patient satisfaction. Concerns about early discharge may also include increased discharge, early termination of breastfeeding and increased parental anxiety. Therefore, based on previous studies shows that postpartum stay in hospital, especially in Iran, is not yet documented, limited study available, the present study is an attempt to fill this research gap to describe discharge time after elective cesarean section on the maternal postpartum outcomes.

\section{Material and methods}

\section{Design and data collection}

This study is a randomized clinical trial that performed on 294 women who undergo elective cesarean section in the Gynecology ward of Imam Sajjad Hospital in Yasuj, Iran during 2018-2019.

According to Tan et al. (2012) [9],(P1:0.52; p0: 0.36; $\alpha=0.05 ; \beta=0.80)$ sample size was estimated at 147 people per group:

$$
n=\frac{\left[Z_{1-a / 2} \sqrt{2 \bar{P}}(1-\bar{P})+Z_{1-\beta} \sqrt{P_{0}\left(1-P_{0}\right)+P_{1}\left(1-P_{1}\right)}\right]^{2}}{\left(P_{1}-P_{0}\right)^{2}}
$$

\section{Sample characteristics}

The inclusion criteria were desire to participate in the study, age less than 35y, elective CS in previous pregnancy, singleton pregnancy, gestation 37 weeks or greater, maternal BMI below 30 (according to weight before pregnancy). The exclusion criteria were having any maternal co-morbidities (i.e. such as immune deficiency, diabetes, hypertension, heart disease, pulmonary and blood disorders), having severe intra-operative or immediate postoperative complications (such as the need for blood transfusion for any reason, fetal anomaly, intolerance to oral liquid diet, postoperative fever), taking any prescription medication, lack of follow-up.

\section{Description of intervention}

Patients were divided into two groups using simple random sampling: Group A) hospital discharge after CS cesarean section for $24 \mathrm{~h}$ ) and group B) hospital discharge after CS cesarean section for $48 \mathrm{~h}$ ).

In both groups, during the first $24 \mathrm{~h}$, cefazolin was administered intravenously (according to the hospital routine) and pethidine was administered during pain. Patients with hematinic and mefenamic acid were discharged from the hospital. It should be noted that no additional procedure, i.e. closing the fallopian tubes was performed.

The primary outcome was patient satisfaction with hospital discharge and pain intensity. Secondary outcomes included surgical site infection, incision separation, endometritis, urinary tract infection, gastrointestinal complications, hospital readmission, delayed postpartum hemorrhage at one and six weeks after hospital discharge.

Follow-up examinations included detailed histories and screening systems to examine patients' wounds for evidence of incision site, drainage from incision, fever symptoms fever symptoms, separation of incision, after additional visits to any medical facility for incision problems or potential related concerns. Participants' vital signs were measured and urine analysis was performed to assess for urinary tract infections.

This study registered at https://en.irct.ir/user/trial/3 9789/view with IRCT registration number IRCT20160524028038N3 in 30/05/2019. 


\section{Measures}

- A check-list was used to collect demographic and delivery information (age, BMI, smoking status, previous $\mathrm{C} / \mathrm{S}$, gravidity, gestational age, $\mathrm{C} / \mathrm{s}$ duration). BMI was measured by weigh $(\mathrm{kg}) / \mathrm{Height}^{2}(\mathrm{~m})$.

- Outcomes including patient satisfaction with their discharge time,surgical site infection, separation of incision, endometritis, urinary tract infection, gastrointestinal complications, rehospitalization, delayed postpartum hemorrhage, severity of pain in one and six weeks after discharge of hospital on discharge day, one and six weeks after cesarean were assessed as followed:

1. Pain and satisfaction: we used Wong-Baker faces scale to measure pain and satisfaction. This scale is used in people aged three years old and more. The scale is graded with even numbers $(0,2,4,6,8$ and 10$)$ including six smiles where the zero smiley indicates no pain, the second smiley indicates 'hurts a little bit', fourth means 'hurts a little more', sixth represents even more problem, eighth indicates 'hurts a whole lot', and the tenth shows 'hurts worst' $[10,11]$. Its validity and reliability are approved [12]. Pain and satisfaction were measured at discharge day, one and six weeks after discharge of hospital.

2. Surgical site infection: having following criteria as Infection within 30 days after operation, partial or total wound dehiscence, presence of purulent or serous wound discharge with induration, warmth/ erythema, tenderness.

3. Separation of incision: any defect in the skin incision of at least $1 \mathrm{~cm}$.

4. Endometritis: Temperature $\geq 38$ on 2 separate occasions; Clinical diagnosis ( $\geq$ one clinical observation) including abnormal uterine tenderness on bimanual examination in absence of other clinical or laboratory findings suggestive of another source of infection, concomitant foulsmelling discharge, tachycardia, leukocytosis.

5. Urinary complications including distension of bladder and urinary tract infection (as $>10^{5}$ bacteria per $\mathrm{mL}$ urine).

6. Gastrointestinal complications: as Nausea, constipation, Abdominal distention and pain

7. Postpartum hemorrhage (PPH): The generally accepted definition of secondary PPH is significant blood loss that occurs between $24 \mathrm{~h}$ and 12 weeks postpartum [13]. Unlike primary PPH, the quantity of blood loss is not specifically described in literature $[14,15]$. The severity is often defined by the need for surgical intervention or blood transfusions [16]. Therefore, in our research, we used the need for surgical intervention or blood transfusions criteria for assess the severity of $\mathrm{PPH}$. Moreover, we used Wong-Baker faces scale for severity of hemorrhage.

\section{Statistical analysis}

Demographic data of the groups were expressed as mean $\pm S D$ or number (percent) and comparison of these data was performed by t-test. The normality of the distributions was evaluated using the KolmogrovSmirnov test. The statistical program for Social Sciences (SPSS, version 21; SPSS, Chicago, IL). $P$ values were set as 0.05 for all analyses. There were no missing values. Therefore, no missing imputation technique was used. This manuscript was prepared in accordance with STROBE guidelines for observational studies.

\section{Results}

a) Baseline characterizes of participant

We assessed 320 subjects for eligibility, among them 26 were excluded for not meeting the inclusion criteria. 294 recruited patients randomly divided to two groups (147 subjects in each group) Group A (discharge $24 \mathrm{~h}$ after CS) and group B (discharge $48 \mathrm{~h}$ after CS). The process of allocating participants during 2019-02-19 until 201907-21 is shown in Fig. 1.

Socio-demographic and clinical characteristic of the patients are presented in Table 1 . There was no significant difference between study groups $(P>0.05)$.

\section{b) Maternal postpartum outcomes between groups}

There was no significant difference in the incidence of surgical site infection, separation of incision, endometritis, urinary tract infection, gastrointestinal complications, rehospitalization, secondary postpartum hemorrhage at one and six weeks after discharge in the study groups $(P>0.05)$. We did not observed any surgical intervention or blood transfusions for controlling secondary postpartum hemorrhage between groups.

The satisfaction scores and pain score at discharge day, one and six weeks after discharge were not significant different in the groups $(P>0.05)$. (Table 2$)$.

\section{Discussion}

In uncomplicated cesarean delivery, the average hospital stay is two to four days, but studies have shown that earlier discharge may be appropriate in women and infants who are correctly selected [17]. Complications of this surgery include infection, wound and fascia opening, metritis, abscess, gastrointestinal complications such as 


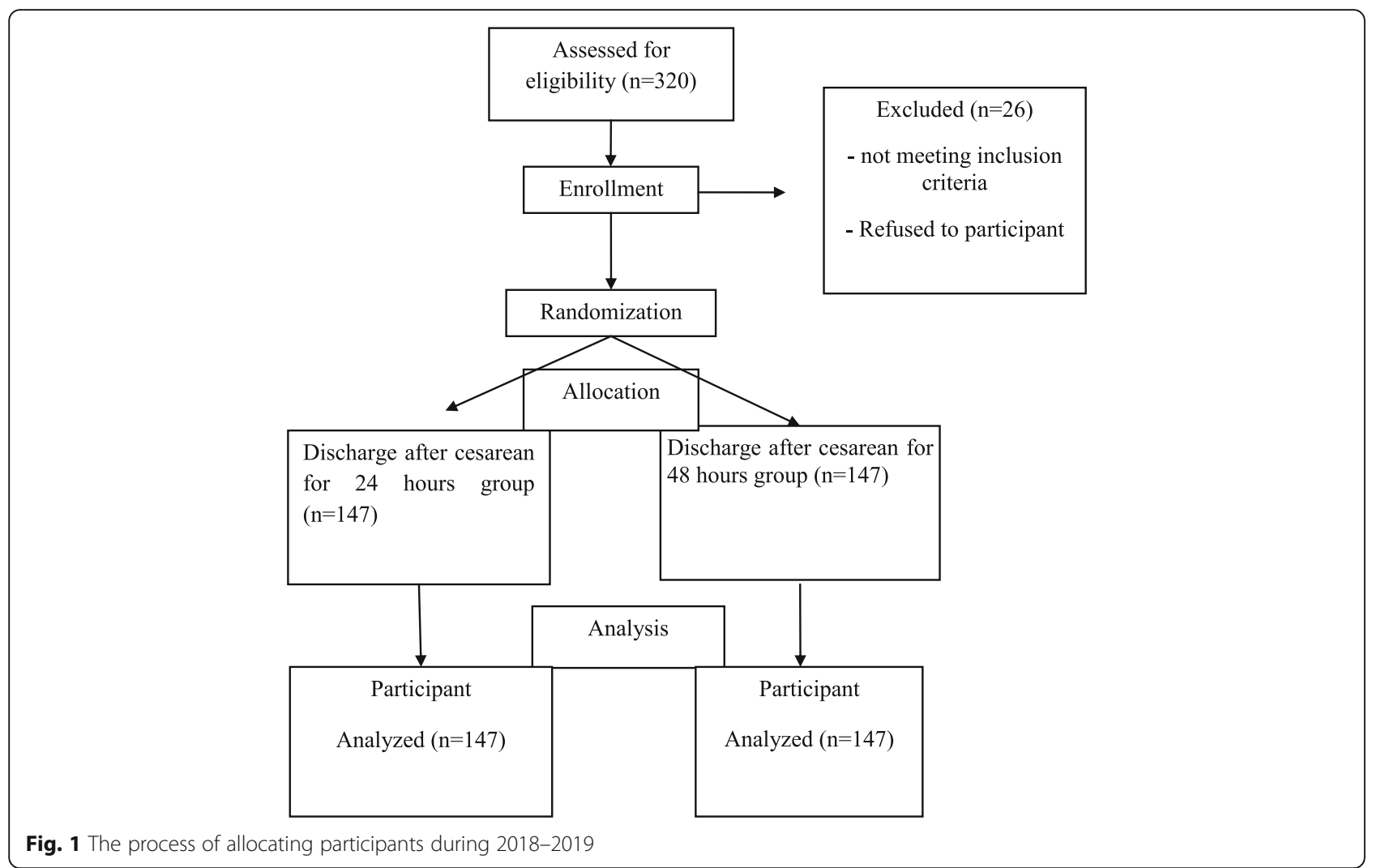

cramping, bloating, constipation, and urinary tract infections [17].

The aim of this study was to evaluate the effects of 24$\mathrm{h}$ and 48-h post-cesarean section discharge. According to the present study, the time of discharge can be reduced to $24 \mathrm{~h}$ after surgery if the mother to be in good general condition, the vital signs are stable and the patient have no underlying problem and disease. Against, the study evidence shows four common health problems, including fatigue, insomnia, breast problems and constipation among Turkish women after early discharge [18]. Women who are discharged early after giving birth are significantly more likely to be depressed than those who

Table 1 Socio-demographic and clinical characteristic of the patients

\begin{tabular}{llll}
\hline Variable & A & B & P value* \\
& $\boldsymbol{n}=\mathbf{1 4 7}$ & $\boldsymbol{n}=\mathbf{1 4 7}$ & \\
\hline Age (year) * & $29.49 \pm 4.07$ & $29.46 \pm 3.82$ & 0.94 \\
BMI* $^{*}$ & $25.41 \pm 12.77$ & $23.49 \pm 2.99$ & 0.07 \\
C/s duration (min) ${ }^{*}$ & $65.00 \pm 0.08$ & $65.00 \pm 0$ & 0.31 \\
Gestational age (day) * & $272.20 \pm 10.20$ & $274.59 \pm 2.63$ & 0.06 \\
Gravity* & $1.34 \pm 0.31$ & $1.27 \pm 0.69$ & 0.36 \\
smoking status & $5(3.40)$ & $3(2.04)$ & 0.12 \\
previous C/S* & $68(46.25)$ & $60(40.81)$ & 0.97 \\
\hline
\end{tabular}

${ }^{*}$ mean $(\mathrm{SD}), \mathrm{T}$ test; ${ }^{* *} \mathrm{~N}(\%), \mathrm{X} 2$ stay longer in the hospital $[19,20]$. Therefore, previous research suggests that early postpartum discharge has a negative effect on women's health. In contrast, several studies show that early postpartum discharge of healthy mothers and full-term infants does not appear to have any side effects if discharge is provided with a policy of offering accompanied by at least one referral to a nursemidwife at home [19]. Our findings have been shown there was no significant difference in the incidence of surgical site infection, separation of incision, endometritis, urinary tract infection, gastrointestinal complications, rehospitalization, secondary postpartum hemorrhage at one and six weeks after discharge in the study groups. In agreements with this study. Katusiime et al. reported that early discharge on the second day after delivery of uncomplicated cesarean section was acceptable for infants and healthy mothers without the need for a home visit [21]. Brown et al. who reported that early discharge for mothers and children does not have a detrimental effect on breastfeeding or postpartum depression [22]. In a study in South Africa in 2017, they examined the effect of $48 \mathrm{~h}$ and 33 to $57 \mathrm{~h}$ postpartum discharge and reported no significant difference in complications between the two groups [23]. In Tan et al. (2012)., day 1 discharge compared with day 2 discharge after a planned cesarean delivery resulted in equivalent outcomes (exclusive breastfeeding, unscheduled maternal or infant 
Table 2 Maternal postpartum outcomes in discharge day, one and six weeks after discharge in the study groups

\begin{tabular}{|c|c|c|c|c|c|c|c|}
\hline \multirow[t]{2}{*}{ Variable } & & & \multicolumn{2}{|l|}{$\begin{array}{l}\text { A } \\
n=147\end{array}$} & \multicolumn{2}{|l|}{$\begin{array}{l}\text { B } \\
n=147\end{array}$} & \multirow[t]{2}{*}{$\begin{array}{l}P \\
\text { value* }\end{array}$} \\
\hline & & & yes & no & yes & no & \\
\hline \multirow[t]{2}{*}{ Surgical site infection } & \multicolumn{2}{|l|}{1 week after discharge } & $1(0.7)$ & $146(99.3)$ & & $147(100)$ & $p=0.31$ \\
\hline & \multicolumn{2}{|l|}{6 weeks after discharge } & $2(1.4)$ & $145(98.6)$ & $3(2)$ & $114(98)$ & $p=0.65$ \\
\hline \multirow[t]{2}{*}{ Endometritis } & \multicolumn{2}{|l|}{1 week after discharge } & 0 & $147(100)$ & 0 & $146(99.3)$ & 0 \\
\hline & \multicolumn{2}{|l|}{6 weeks after discharge } & 0 & $147(100)$ & 0 & $147(100)$ & - \\
\hline \multirow[t]{2}{*}{ Separation of incision } & \multicolumn{2}{|l|}{1 week after discharge } & $1(0.7)$ & $146(99.3)$ & $0(0)$ & $147(100)$ & 0.3 \\
\hline & \multicolumn{2}{|l|}{6 weeks after discharge } & $2(1.4)$ & $145(98.6)$ & $1(0.7)$ & $146(99.3)$ & 0.56 \\
\hline \multirow[t]{2}{*}{ Rehospitalization } & \multicolumn{2}{|l|}{1 week after discharge } & 4 & 143 & 2 & 145 & 0.06 \\
\hline & \multicolumn{2}{|l|}{6 weeks after discharge } & 3 & 144 & 3 & 144 & - \\
\hline \multirow[t]{2}{*}{ Urinary tract infection } & \multicolumn{2}{|l|}{1 week after discharge } & $14(9.5)$ & $133(90.5)$ & $17(11.6)$ & $130(88.4)$ & $p=0.56$ \\
\hline & \multicolumn{2}{|l|}{6 weeks after discharge } & $3(2.04)$ & $144(97.95)$ & $2(1.36)$ & $145(98.63)$ & $P=0.43$ \\
\hline \multirow[t]{8}{*}{ Gastrointestinal complications } & \multirow[t]{2}{*}{ Abdominal pain } & 1 week after discharge & $6(4.1)$ & $141(95.9)$ & $5(3.4)$ & $142(96.6)$ & $p=0.75$ \\
\hline & & 6 weeks after discharge & $3(2.04)$ & 144 (97.99) & $1(0.69)$ & $146(99.31)$ & $\mathrm{P}=/ 53$ \\
\hline & \multirow[t]{2}{*}{ Abdominal distention } & 1 week after discharge & $19(12.9)$ & $128(87.1)$ & $14(9.5)$ & $133(90.5)$ & $p=0.35$ \\
\hline & & 6 weeks after discharge & $2(1.36)$ & 145 (98.63) & $2(1.36)$ & $145(98.63)$ & - \\
\hline & \multirow[t]{2}{*}{ Constipitation } & 1 week after discharge & $9(6.1)$ & $138(93.9)$ & $14(9.5)$ & $133(90.5)$ & $p=0.27$ \\
\hline & & 6 weeks after discharge & $3(2.04)$ & 144 (97.99) & $2(1.36)$ & $145(98.63)$ & $P=/ 55$ \\
\hline & \multirow[t]{2}{*}{ Nausea } & 1 week after discharge & & $147(100)$ & & $147(100)$ & \\
\hline & & 6 weeks after discharge & $0(0)$ & $147(100)$ & $0(0)$ & $147(100)$ & - \\
\hline \multirow[t]{2}{*}{ Secondary postpartum hemorrhage severity } & \multicolumn{2}{|l|}{1 week after discharge } & \multicolumn{2}{|c|}{$6.34 \pm 1.21$} & \multicolumn{2}{|c|}{$6.49 \pm 1.87$} & 0.41 \\
\hline & \multicolumn{2}{|l|}{6 weeks after discharge } & \multicolumn{2}{|l|}{0} & \multicolumn{2}{|l|}{0} & - \\
\hline Satisfaction score & Day of discharge & & $3.30 \pm 1.23$ & & $3.82 \pm 3.45$ & & 0.08 \\
\hline & 1 week after discharge & & $2.29 \pm 1.50$ & & $2.54 \pm 1.68$ & & 0.17 \\
\hline & 6 weeks after discharge & & $1.85 \pm 1.23$ & & $1.86 \pm 1.18$ & & 0/92 \\
\hline Pain score & Day of discharge & & $1.43 \pm 0.11$ & & $1.23 \pm 0.10$ & & 0.17 \\
\hline & 1 week after discharge & & $1.85 \pm 1.68$ & & $1.99 \pm 1.69$ & & 0.47 \\
\hline & 6 weeks after discharge & & $1.73 \pm 0.70$ & & $1.36 \pm 0.76$ & & 0/98 \\
\hline
\end{tabular}

medical consultations, rehospitalizations, maternal antibiotic use, and maternal well-being, anxiety, and depression status) [9].

Since the 1990s, in most health care centers, measuring patient satisfaction has been considered as a way of receiving patients' views and opinions about their care [24, 25]. In this study, patient satisfaction was assessed in both groups after the intervention. Another key finding of this paper is that satisfaction and pain score was not significantly different at discharge day, one and six weeks after discharge of hospital. In the study which conducted by that Tan et al. (2012)., the patient satisfaction evaluated in one day postoperative and two days postoperative groups and they reported there was no significant difference between the two groups [9].

Our study has several strengths including randomization (and successful randomization since both groups similar), greater sample size using standard measures for accurate assessment of pain and satisfaction and the inclusion control group for comparison. There are some limitations. Our study was limited to an only low-risk population from hospital this, in turn, limits generalization the finding to the whole population and external validity. Further studies with larger sample size recruited from a less homogenous population are recommended.

\section{Conclusion}

In conclusion, according to the present study and data from previous studies, if the mother is in good general condition, with stable vital signs without any underlying problem and disease, the time of discharge from the hospital can reduced to $24 \mathrm{~h}$ after surgery.

Acknowledgements

Not Applicable. 


\section{Authors' contributions}

PGH, RV,SHA,L,FB contributed in conception, design and drafting of the manuscript. PGH, L contributed in data collection. PGH, RV,SHA,L,FB,MAGH contributed in manuscript drafting. All authors approved the final version for submission. PGH and FB oversaw the study.

\section{Authors' information}

Not Applicable.

\section{Funding}

Yasuj University of Medical Sciences.

\section{Availability of data and materials}

The primary data for this study is available from the authors on direct request.

\section{Declarations}

\section{Ethics approval and consent to participate}

It was approved by the ethics committee of Yasuj University of Medical Sciences Ethics Committee, Iran (IR.YUMS.REC.1397.134). Written informed consent was obtained from all participating women and their husband; all participants were aware that they could withdraw at any point during the trial. All methods were performed in present study are in accordance with the relevant Iran Ministry of Health guideline and regulations.

\section{Consent for publication}

Not applicable.

\section{Competing interests}

The authors declare no conflict of interest.

\section{Author details}

'Department of Gynecology and Obstetrics, Yasuj University of Medical Sciences, Yasuj, Iran. ${ }^{2}$ Social Determinants of Health Research Center, Yasuj University of Medical Sciences, Yasuj, Iran. ${ }^{3}$ Department of Parasitology, Yasuj University of Medical Sciences, Yasuj, Iran.

Received: 2 January 2021 Accepted: 11 May 2021

Published online: 30 June 2021

\section{References}

1. MacDorman MF, Menacker F, Declercq E. Cesarean birth in the United States: epidemiology, trends, and outcomes. Clin Perinatol. 2008;35(2):293307. https://doi.org/10.1016/j.clp.2008.03.007.

2. Organization $\mathrm{wH}$. Appropriate technology for birth. Lancet. 1985;2(8452): $436-7$.

3. Martell LK. The hospital and the postpartum experience: a historical analysis. J Obstet Gynecol Neonatal Nurs. 2000;29(1):65-72. https://doi.org/10.1111/j.1 552-6909.2000.tb02757.x

4. OMR A, Cegolon L, Macleod D, Benova L. Length of stay after childbirth in 92 countries and associated factors in 30 low- and middle-income countries: compilation of reported data and a cross-sectional analysis from nationally representative surveys. PLoS Med. 2016:13(3):e1001972.

5. Catz C, Hanson JW, Simpson L, Yaffe SJ. Summary of workshop: early discharge and neonatal hyperbilirubinemia. Pediatrics. 1995:96(4):743 LP-745

6. Malkin JD, Garber S, Broder MS, Keeler E. Infant mortality and early postpartum discharge. Obstet Gynecol. 2000;96(2):183-8 Available from: http://www.ncbi.nlm.nih.gov/pubmed/10908760.

7. Fasubaa OB, Ogunniyi SO, Dare FO, Isawumi Al, Ezechi OC, Orji EO. Uncomplicated caesarean section: is prolonged hospital stay necessary? East Afr Med J. 2000;77(8):448-51.

8. Umbeli T, Elwahab R, Ismail S, Khadeja S, Basher N. Assessment of discharge after 24 hours following elective caesarean section in Omdurman Maternity Hospital, Sudan, 2010. Sudan JMS. 2012;Volume 7(4):215-8.

9. Tan PC, Norazilah MJ, Omar SZ. Hospital discharge on the first compared with the second day after a planned cesarean delivery: a randomized controlled trial. Obstet Gynecol. 2012;120(6):1273-82. https://doi.org/10.1 097/AOG.0b013e3182723a95.
10. Hockenberry MJ, Wilson D. Wong s Essentials of Pediatric Nursing. 6th ed. St Louis: Mosby Elsevier; 2001. p. 1301

11. Gondring WH, Trepman E, Shields B. Tarsal tunnel syndrome: assessment of treatment outcome with an anatomic pain intensity scale. Foot Ankle Surg. 2009;15(3):133-8. https://doi.org/10.1016/j.fas.2008.10.003.

12. Fadayevatan R, Alizadeh-Khoei M, Hessami-Azar ST, Sharifi F, Haghi M, Kaboudi B. Validity and Reliability of 11-face Faces Pain Scale in the Iranian Elderly Community with Chronic Pain. Indian J Palliat Care. 2019;25(1):46-51. https://doi.org/10.4103/IJPC.IJPC_126_18.

13. Abdul-Kadir R, McLintock C, Ducloy AS, El-Refaey $H$, England A, Federici AB, et al. Evaluation and management of postpartum hemorrhage: consensus from an international expert panel. Transfusion. 2014;54(7):1756-1768. doi: 10.111/trf.12550. Epub 2014 Mar 12.

14. Dossou M, Debost-Legrand A, Déchelotte P, Lémery D, Vendittelli F. Severe secondary postpartum hemorrhage: a historical cohort. Birth. 2015:42(2): 149-55. https://doi.org/10.1111/birt.12164 Epub 2015 Apr 13.

15. Hoveyda F, MacKenzie IZ. Secondary postpartum haemorrhage: incidence, morbidity and current management. Bjog. 2001;108(9):927-30. https://doi. org/10.1111/j.471-0528.2001.00230.x.

16. Debost-Legrand A, Rivière $O$, Dossou M, Vendittelli F. Risk factors for severe secondary postpartum hemorrhages: a historical cohort study. Birth. 2015; 42(3):235-41. https://doi.org/10.1111/birt.12175 Epub 2015 May 29.

17. Leveno KJ, Spong CY, Dashe JS, Casey BM, Hoffman BL, Cunningham FG, et al. Williams Obstetrics, 25th Edition McGraw-Hill Education 2018, p. 1292

18. Gözüm S, Kiliç D. Health problems related to early discharge of Turkish women. Midwifery. 2005;21(4):371-8. https://doi.org/10.1016/j.midw.2005. 02.005 .

19. Brown S, Lumley J. Reasons to stay, reasons to go: results of an Australian population-based survey. Birth. 1997;24(3):148-58. https://doi.org/10.1111/j.1 523-536X.1997.00148.pp.X.

20. Bravo P, Uribe C, Contreras A. Early postnatal hospital discharge: the consequences of reducing length of stay for women and newborns. Rev Esc Enferm USP. 2011;45(3):758-63. https://doi.org/10.1590/S0080-62342011 000300030

21. Katusiime COP, Kambugu A. Early discharge from hospital after caesarean section at Chris Hani Baragwanath hospital. S Afr J Obstet Gynaecol. 2011; 17(1):17-8.

22. Brown S, Small R, Faber B, Krastev A, Davis P. Early postnatal discharge from hospital for healthy mothers and term infants. Cochrane Database Syst Rev. 2002;3(10).

23. Buchmann EJ, Pillay N. Early discharge from hospital after caesarean section at Chris Hani Baragwanath Hospital. S Afr J Obstetrics and Gynaecology 2011;17(1):17.

24. Huston CJ. Outcomes measurement in healthcare: New imperatives for professional nursing practice. Nurs Case Manage. 1999;4:188-95.

25. Wiechers DO, Wiechers DK. Demonstrating quality: Clinical outcome, functional status, patient satisfaction, value, and efficiency. Clin Rehabil Psychiatr Pract. 1996;7:167-83.

\section{Publisher's Note}

Springer Nature remains neutral with regard to jurisdictional claims in published maps and institutional affiliations.

Ready to submit your research? Choose BMC and benefit from:

- fast, convenient online submission

- thorough peer review by experienced researchers in your field

- rapid publication on acceptance

- support for research data, including large and complex data types

- gold Open Access which fosters wider collaboration and increased citations

- maximum visibility for your research: over $100 \mathrm{M}$ website views per year

At $\mathrm{BMC}$, research is always in progress.

Learn more biomedcentral.com/submissions 